\title{
Microtubule-Associated Protein-2 and Class III $\beta$-Tubulin Are Expressed in Extraskeletal Myxoid Chondrosarcoma
}

\author{
Masanori Hisaoka, M.D., Sumika Okamoto, M.D., Shune Koyama, D.D.S., Tsuyoshi Ishida, M.D., \\ Tetsuo Imamura. M.D., Hiroaki Kanda, M.D., Toru Kameya, M.D., Jeanne. M. Meis-Kindblom, M.D., \\ Lars-Gunnar Kindblom, M.D., Ph.D., Hiroshi Hashimoto, M.D. \\ Department of Pathology and Oncology (MH, SO, SK, HH), School of Medicine, University of Occupational \\ and Environmental Health, Kitakyushu, Japan; Department of Pathology (TsI), Tokyo Medical University, \\ Tokyo, Japan; Department of Surgical Pathology (TeI), School of Medicine, Teikyo Medical University, \\ Tokyo, Japan; Department of Pathology (HK), Cancer Institute, Japanese Foundation for Cancer Research, \\ Tokyo, Japan; Department of Pathology (TK), Kitasato University School of Medicine, Sagamihara, Japan; \\ and Department of Pathology (JMMK, LGK), Sahlgren University Hospital, Göteborg, Sweden
}

Extraskeletal myxoid chondrosarcoma is a rare soft tissue sarcoma of uncertain histogenetic origin. Because recent reports have indicated neural-neuroendocrine differentiation in some extraskeletal myxoid chondrosarcomas, we investigated 25 tumors for expressions of microtubule-associated protein-2 and Class III $\beta$-tubulin, which are major components of microtubules and specifically localized in neurons and their derivatives. Immunohistochemical expression of microtubule-associated protein-2 and Class III $\beta$-tubulin was studied in extraskeletal myxoid chondrosarcomas using formalin-fixed, paraffin-embedded tissues. Cytoplasmic expressions of microtubule-associated protein-2 and Class III $\beta$-tubulin were detected in $21(84 \%)$ and $13(52 \%)$ of the 25 extraskeletal myxoid chondrosarcomas, respectively, although the number of positively stained tumor cells varied. Expression of the Class III $\beta$-tubulin gene was also assessed in two immunohistochemically positive cases by in situ hybridization using an oligonucleotide probe specific for its transcript, and both cases showed expression of Class III $\beta$-tubulin transcript.

\footnotetext{
Copyright (C) 2003 by The United States and Canadian Academy of Pathology, Inc.

VOL. 16, NO. 5, P. 453, 2003 Printed in the U.S.A

Date of acceptance: February 13, 2003.

Supported in part by 2000 Grants-in-Aid for Scientific Research (C) (no. 12670184) from the Japan Society of the Promotion of Science and for cancer research from the Fukuoka Cancer Society, Fukuoka, Japan. Presented in part at the 91st Annual Meeting of the U.S. and Canadian Academy of Pathology, February 23-March 1, 2002, Chicago, Illinois, and published in abstract form in Modern Pathology 2002;15:15A.

Address reprint requests to: Hiroshi Hashimoto, M.D., Department of Pathology and Oncology, School of Medicine, University of Occupational and Environmental Health, 1-1 Iseigaoka, Yahatanishi-ku, Kitakyushu 807-8555, Japan; fax: 93-692-0189; e-mail: hiroshi@med.uoeh-u.ac.jp.

DOI: 10.1097/01.MP.0000067422.61241.64
}

Another case was examined with immunoelectron microscopy, and immunogold particles for Class III $\beta$-tubulin were localized to microtubular aggregates. Our data indicate that microtubules in extraskeletal myxoid chondrosarcoma are similar to those found in neurons, further supporting the concept that neural-neuroendocrine differentiation occurs in a significant number of extraskeletal myxoid chondrosarcoma.

KEY WORDS: Extraskeletal myxoid chondrosarcoma, Microtubule, Microtubule-associated protein, Tubulin.

Mod Pathol 2003;16(5):453-459

Extraskeletal myxoid chondrosarcoma is a rare soft tissue sarcoma with distinct clinicopathologic and cytogenetical features (1-8). It is typically myxoid and arises in the deep soft tissue of the proximal extremities and limb girdles of middle-aged adults (1-4). Characteristic chromosomal translocations including $\mathrm{t}(9 ; 22)(\mathrm{q} 22 ; \mathrm{q} 12)$, resulting in a fusion of the EWS gene at 22q12 and the CHN/TEC gene at 9q22, have been reported in extraskeletal myxoid chondrosarcoma, as well as two other less common rearrangements, including fusion of the EWSrelated gene TAF2N to CHN/TEC and fusion of the $\mathrm{NH} 2$-terminal domain of the basic helix-loop-helix protein TCF12 to CHN/TEC (5-8). Extraskeletal myxoid chondrosarcoma has generally been regarded as a chondroid tumor because of morphologic similarities between extraskeletal myxoid chondrosarcoma and embryonic chondrogenesis, the presence of chondroitin-4 and 6-sulfate in its myxoid matrix, frequent $S-100$ protein positivity, and Type II collagen synthesis by tumor cells (1, 
9-13). However, its chondroid nature has been questioned because it is an extraskeletal tumor lacking discernible hyaline cartilage. In addition, recent ultrastructural identification of dense core granules as well as immunohistochemical detection of synaptophysin, chromogranin A, and PGP9.5 indicate that some extraskeletal myxoid chondrosarcomas exhibit neuroendocrine-neural differentiation $(3,13-15)$.

Microtubular aggregates within rough endoplasmic reticulum are a characteristic ultrastructural finding of extraskeletal myxoid chondrosarcoma, with at least one third of the tumors reported to show these structures $(5,6,16)$. Microtubules have crucial biological functions, including mediating mitosis, intracellular transport, and cell motility.

Tubulin is a major constituent protein of microtubules and consists of two $50-\mathrm{kDa}$ subunits designated as $\alpha$ and $\beta$. Expression of Class III $\beta$-tubulin, one of the six isotypes of the $\beta$ subunit expressed in mammals (17), is restricted almost entirely to neurons with the known exception of Sertoli cells in the testis (18-20).

Microtubule-associated proteins (MAP) are major components of a family of cytoskeletal proteins associated with microtubule assembly and are implicated in key roles in morphogenesis, function, and maintenance of the nervous system (21). MAP-2, including high-molecular-weight MAP-2 (MAP-2a, MAP-2b) and low-molecular-weight MAP-2 (MAP-2c, MAP-2d), is the most abundant MAP isoform in the brain and is primarily localized to neuronal dendrites $(22,23)$. However, it recently has been reported that MAP-2 is expressed in the companion layer of the anagen hair follicle (24).

Class III $\beta$-tubulin and MAP-2 have been used as sensitive and specific markers for neural differentiation, and a variety of neural or neuroendocrine tumors such as neuroblastoma, medulloblastoma, central neurocytoma, ganglioglioma, dysembryoplastic neuroepithelial tumor, pulmonary carcinoid, and small cell carcinoma have been shown to express Class III $\beta$-tubulin and/or MAP-2 (23, 25, 26). However, the expression of these molecules has been demonstrated also in variable fractions of non-neural or non-neuroendocrine tumors such as astrocytoma, pulmonary squamous cell carcinoma, and adenocarcinoma (25-27).

The aim of our study was to assess neural-neuroendocrine differentiation in extraskeletal myxoid chondrosarcoma using microtubule-related proteins, Class III $\beta$-tubulin, and MAP-2 as specific markers.

\section{MATERIALS AND METHODS}

Twenty-five cases of extraskeletal myxoid chondrosarcoma were retrieved from the institutional pathology files of all of the authors. Detailed clinicopathologic and molecular features of some of these cases have been described elsewhere $(2,7,8)$.

Four- $\mu \mathrm{m}$-thick sections of representative formalin-fixed, paraffin-embedded tissues of extraskeletal myxoid chondrosarcoma were prepared and used for immunohistochemical analysis and in situ hybridization. Normal cerebral tissue was included as a positive control in both analyses. Sixteen other myxoid or chondroid tumors (3 myxoid liposarcomas, 3 myxoid malignant fibrous histiocytomas, 3 soft tissue myxomas, 2 enchondromas, 2 chondrosarcomas, and 3 chordomas) were also analyzed immunohistochemically for expressions of MAP-2 and Class III $\beta$-tubulin.

Standard antigen retrieval with a microwave oven was performed on deparaffinized sections. After treatments with $3 \%$ hydrogen peroxide for 10 minutes and normal goat serum for 5 minutes, the sections were incubated with commercialized monoclonal antibodies raised against MAP-2 (AP-20; Sigma, Saint Louis, MO, dilution 1:200) and Class III $\beta$-tubulin (TUJ1; BabCO, Richmond, CA, dilution 1:400) for 16 hours at $4^{\circ} \mathrm{C}$. Although the expression of Class III $\beta$-tubulin appears to be limited to neuronal tissues, this molecule has been detected in some non-neuronal tumors such as pulmonary squamous cell carcinoma with the antibody TUJ1 (25). However, this immunoreactivity might have been antibody clone dependent, because another clone (TU-20) of the antibody raised against Class III $\beta$-tubulin has failed to support this finding (23). The labeled streptavidin-biotin-peroxidase complex method (LSAB kit; DAKO Japan, Kyoto, Japan) was used for immunostaining followed by visualization with 3,3'-diaminobenzidine. Immunostaining results of tumor cells were tabulated as follows: focal, $5 \%$ to less than one third positively staining cells; moderate, one third to less than two thirds positively staining cells; and diffuse, two thirds or more positively staining tumor cells.

In two extraskeletal myxoid chondrosarcomas that were immunohistochemically positive for MAP-2 and Class III $\beta$-tubulin, the gene expression of Class III $\beta$-tubulin was investigated by in situ hybridization using digoxigenin-end-labeled oligonucleotide probes flanking parts (45 bases) of exons 3 and 4 of human Class III $\beta$-tubulin mRNA (GenBank accession no. AF427491): antisense probe 5'-ACTCTGACCAAAGATGAAATTGTCAGGCCTGAAGAGATGTCCAAA, sense probe 5'-TTTGGACATCTCTTCAGGCCTGACAATTTCATCTTTGGTCAGAGT. After treatment with $50 \mu \mathrm{g} / \mathrm{mL}$ proteinase $\mathrm{K}$ (Sigma) for 15 minutes at $37^{\circ} \mathrm{C}$, the sections were postfixed in $4 \%$ paraformaldehyde, neutralized with $2 \mathrm{mg} / \mathrm{mL}$ glycine in phosphate buffered saline, and immersed in $40 \%$ formamide. Hybridization was carried out in $40 \%$ formamide, $10 \mathrm{mmol} / \mathrm{L}$ Tris- $\mathrm{HCl}(\mathrm{pH} 8.0), 0.6 \mathrm{~mol} / \mathrm{L}$ $\mathrm{NaCl}, 1 \mathrm{mmol} / \mathrm{L}$ EDTA, $1 \times$ Denhardt's solution (Sig- 
TABLE 1. Immunohistochemical Results of MAP-2 and Class III $\beta$-Tubulin in Myxoid and Chondroid Tumors

\begin{tabular}{|c|c|c|c|c|c|c|c|}
\hline \multirow{2}{*}{ Tumor* } & \multirow{2}{*}{$\begin{array}{c}\text { Number of Cases } \\
\text { Examined }\end{array}$} & \multicolumn{3}{|c|}{ MAP-2 } & \multicolumn{3}{|c|}{ Class III $\beta$-Tubulin } \\
\hline & & Focal & Moderate & Diffuse & Focal & Moderate & Diffuse \\
\hline EMCS & 25 & 11 & 8 & 2 & 8 & 5 & 0 \\
\hline Soft tissue myxoma & 3 & 1 & 0 & 0 & 0 & 0 & 0 \\
\hline Myxoid liposarcoma & 3 & 0 & 0 & 0 & 0 & 0 & 0 \\
\hline Myxoid MFH & 3 & 0 & 2 & 0 & 1 & 0 & 0 \\
\hline Enchondroma & 2 & 0 & 2 & 0 & 0 & 0 & 0 \\
\hline Chondrosarcoma & 2 & 0 & 2 & 0 & 1 & 0 & 0 \\
\hline Chordoma & 3 & 0 & 0 & 3 & 0 & 2 & 0 \\
\hline
\end{tabular}

* EMCS = extraskeletal myxoid chondrosarcoma; MFH = malignant fibrous histiocytoma.

Focal, positive tumor cells $<1 / 3$; moderate, $1 / 3<$ positive tumor cells $<2 / 3$; diffuse, $2 / 3<$ positive tumor cells.

ma), $250 \mu \mathrm{g} / \mathrm{mL}$ yeast tRNA, $125 \mu \mathrm{g} / \mathrm{mL}$ salmon sperm DNA, and $10 \%$ dextran sulfate, together with 1 $\mu \mathrm{g}$ of the labeled probe for 16 hours at $42^{\circ} \mathrm{C}$. After hybridization, the sections were rinsed briefly with $50 \%$ formamide in $2 \times$ SSC and washed 5 times with the same washing solution for 1 hour at $37^{\circ} \mathrm{C}$, followed by $2 \times$ SSC for 15 minutes. at room temperature. Signal detection was performed using a monoclonal anti-digoxigenin antibody (21H8; Abcam, Cambridge, UK) and a polymeric conjugate made up of a large number of peroxidase and secondary antibody molecules (EnVision, DAKO Japan) according to the manufacturer's instructions. Positive signals were visualized with 3,3'-diaminobenzidine. Specificity of the antisense probe was attested by a positive hybridization signal to cDNA of human brain tissue blotted on a nylon filter membrane (Amersham Pharmacia Biotech, Tokyo, Japan) and negativity in genomic human DNA and products (247 bp) of polymerase chain reaction for transcripts of human phosphoglycerate kinase gene on the same membrane.

One of the cases immunohistochemically positive for Class III $\beta$-tubulin was further investigated using immunoelectron microscopy. Small pieces of the specimen were cut from the formalin-fixed tumor tissue and thoroughly washed with phosphate buffered saline at $4^{\circ} \mathrm{C}$. The specimen was dehydrated with a graded series of dimethylformamide at $-20^{\circ} \mathrm{C}$ and embedded in Lowicryl K4M (Chemische Werke Lowi, Waldkraiburg, Germany), which was polymerized by ultraviolet irradiation at $-20^{\circ} \mathrm{C}$. Ultrathin sections were mounted on nickel grids coated with $0.5 \%$ formvar (Nisshin EM, Tokyo, Japan) and incubated with the primary antibody (TUJ1, 1:50) at $4^{\circ} \mathrm{C}$ overnight. Fifteen-nanometer gold particles conjugated with anti-mouse IgG antibody (BBInternational, Cardiff, UK) were applied for 30 minutes at room temperature, followed by brief double staining with uranyl acetate and lead citrate. The primary antibody was omitted from the procedure in a negative control.

\section{RESULTS}

Immunohistochemical staining results of all tumors are summarized in Table 1 , and detailed re- sults as well as molecular findings of the fusion genes in each case of extraskeletal myxoid chondrosarcoma are shown in Table 2.

Cytoplasmic expression of MAP-2 and Class III $\beta$-tubulin was detected immunohistochemically in 21 cases $(84 \%)$ and 13 cases $(52 \%)$ of 25 cases, respectively. Diffuse (more than two thirds of tumor cells) and mostly intense staining for MAP-2 was seen in two cases, whereas eight cases showed moderate positive staining (one third to two thirds of tumor cells) (Fig. 1). Moderate immunohistochemical staining for Class III $\beta$-tubulin was seen in five cases, and focal positive staining, in 8 cases. Co-expression of MAP- 2 and Class III $\beta$-tubulin was noted in 10 of 25 cases (40\%).

Focal MAP-2 expression was seen in one of three soft tissue myxomas, and moderate MAP-2 expression, in two of three myxoid malignant fibrous histiocytomas; one of these malignant fibrous histiocytomas also focally expressed Class III $\beta$-tubulin.

TABLE 2. Immunohistochemical Results and Molecular Features of 25 Extraskeletal Myxoid Chondrosarcomas

\begin{tabular}{|c|c|c|c|}
\hline \multirow{2}{*}{$\begin{array}{c}\text { Number of } \\
\text { Cases }\end{array}$} & \multicolumn{2}{|c|}{ Immunohistochemistry } & \multirow[b]{2}{*}{ Fusion Gene } \\
\hline & MAP-2 & $\begin{array}{c}\text { Class III } \\
\beta \text {-Tubulin }\end{array}$ & \\
\hline 1 & Focal & Moderate & TAF2N-CHN \\
\hline 2 & Focal & Negative & EWS-CHN type 1 \\
\hline 3 & Diffuse & Moderate & EWS-CHN type 1 \\
\hline 4 & Focal & Negative & EWS-CHN type 1 \\
\hline 5 & Moderate & Focal & EWS-CHN type 1 \\
\hline 6 & Negative & Focal & EWS-CHN type 1 \\
\hline 7 & Focal & Focal & EWS-CHN type 1 \\
\hline 8 & Diffuse & Focal & EWS-CHN type 1 \\
\hline 9 & Negative & Focal & EWS-CHN type 1 \\
\hline 10 & Negative & Negative & Not detected \\
\hline 11 & Focal & Moderate & Not detected \\
\hline 12 & Negative & Focal & EWS-CHN type 2 \\
\hline 13 & Focal & Negative & EWS-CHN type 1 \\
\hline 14 & Focal & Negative & TAF2N-CHN \\
\hline 15 & Focal & Negative & EWS-CHN type 1 \\
\hline 16 & Moderate & Focal & EWS-CHN type 1 \\
\hline 17 & Focal & Negative & Not detected \\
\hline 18 & Focal & Focal & Not examined \\
\hline 19 & Focal & Negative & Not examined \\
\hline 20 & Moderate & Negative & Not examined \\
\hline 21 & Moderate & Moderate & Not examined \\
\hline 22 & Moderate & Moderate & Not examined \\
\hline 23 & Moderate & Negative & Not examined \\
\hline 24 & Moderate & Negative & Not examined \\
\hline 25 & Moderate & Negative & Not detected \\
\hline
\end{tabular}




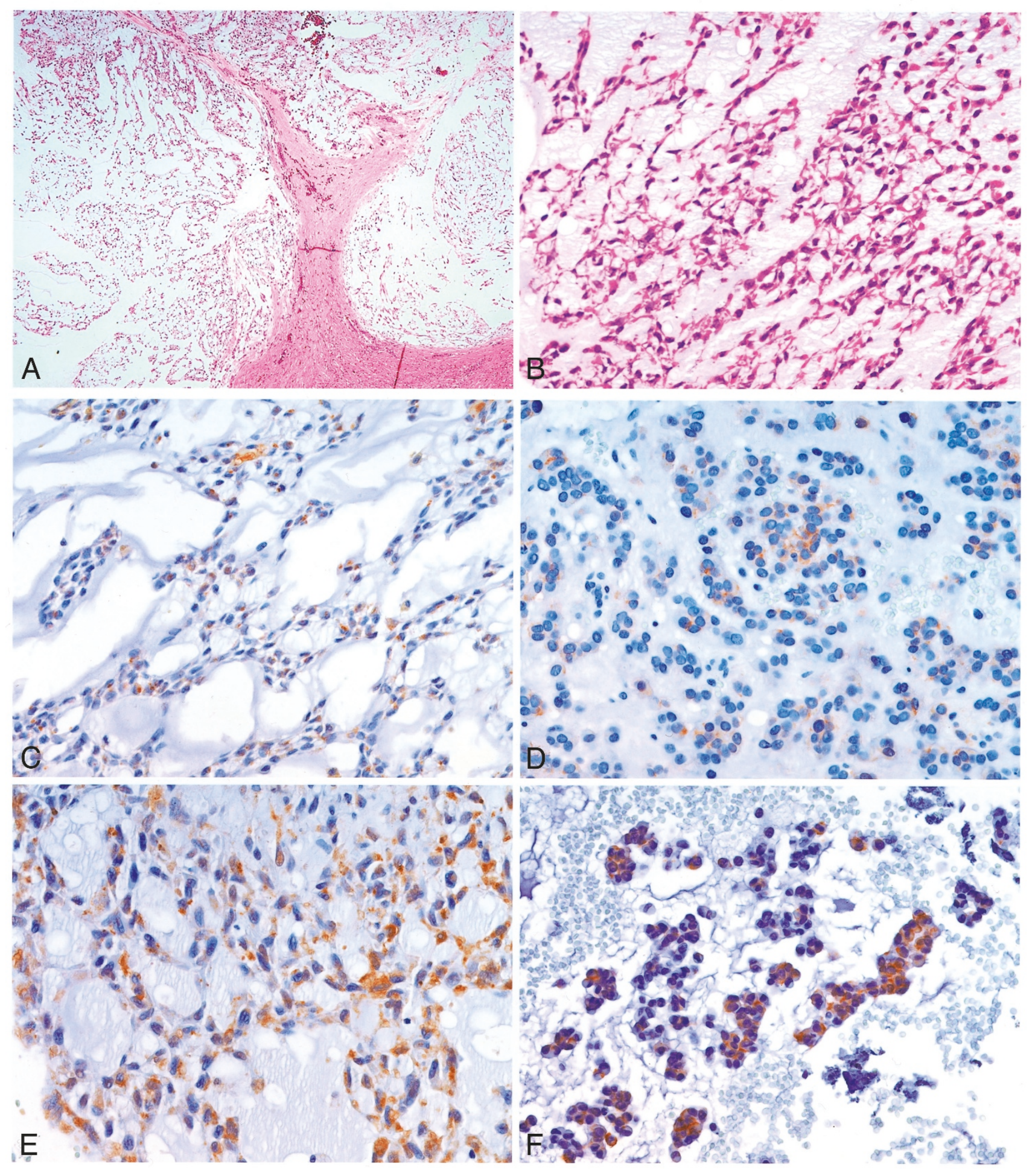

FIGURE 1. Morphology of EMCS (A, B) and immunohistochemical expression of Class III $\beta$-tubulin (C, D) and MAP-2 (E, F).

In contrast, all 7 chondroid tumors showed moderate to diffuse expression of MAP-2 (Fig. 2). One of two chondrosarcomas and two of three chordomas also expressed Class III $\beta$-tubulin focally to moderately (Fig. 2).

In situ hybridization performed in two extraskeletal myxoid chondrosarcomas using the antisense probe demonstrated positive signals for Class III $\beta$-tubulin in tumor cells of both cases; focal or moderate immunohistochemical expression of MAP-2 and Class III $\beta$-tubulin was identified in these cases (Fig. 3).

The extraskeletal myxoid chondrosarcoma analyzed with immunoelectron microscopy showed prominent microtubular aggregates within variably dilated cisternae. Immunogold particles for Class III 

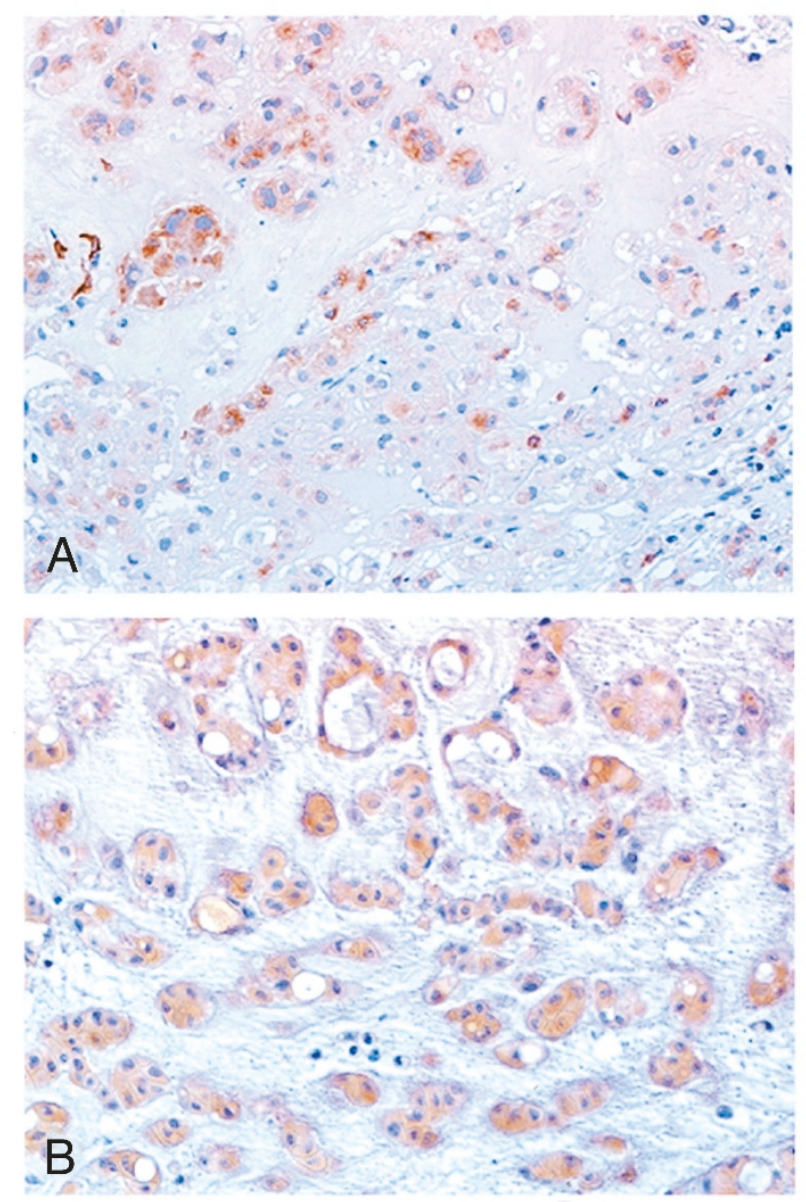

FIGURE 2. Chordoma with immunohistochemical expression of class III $\beta$-tubulin (A) and MAP-2 (B).

$\beta$-tubulin were localized primarily to these microtubular aggregates (Fig. 4).

\section{DISCUSSION}

The recent detection of dense core granules ultrastructurally as well as synaptophysin, chromogranin A, neuron-specific enolase, PGP9.5, and CD57 (Leu 7) immunohistochemically in some extraskeletal myxoid chondrosarcomas has raised the possibility of neural-neuroendocrine differentiation in extraskeletal myxoid chondrosarcoma and has posed further questions regarding its chondroid nature $(3,4,13-15)$. In addition, the recent immunohistochemical detection of peripherin in extraskeletal myxoid chondrosarcoma, a type IIIintermediate filament involved in the growth and development of the peripheral nervous system, as well as tau, an axonal protein promoting tubulin polymerization, has provided additional support for the notion of limited neural differentiation in extraskeletal myxoid chondrosarcoma $(28,29)$. Our immunohistochemical and immunoelectron microscopy findings of the expression of neuron-

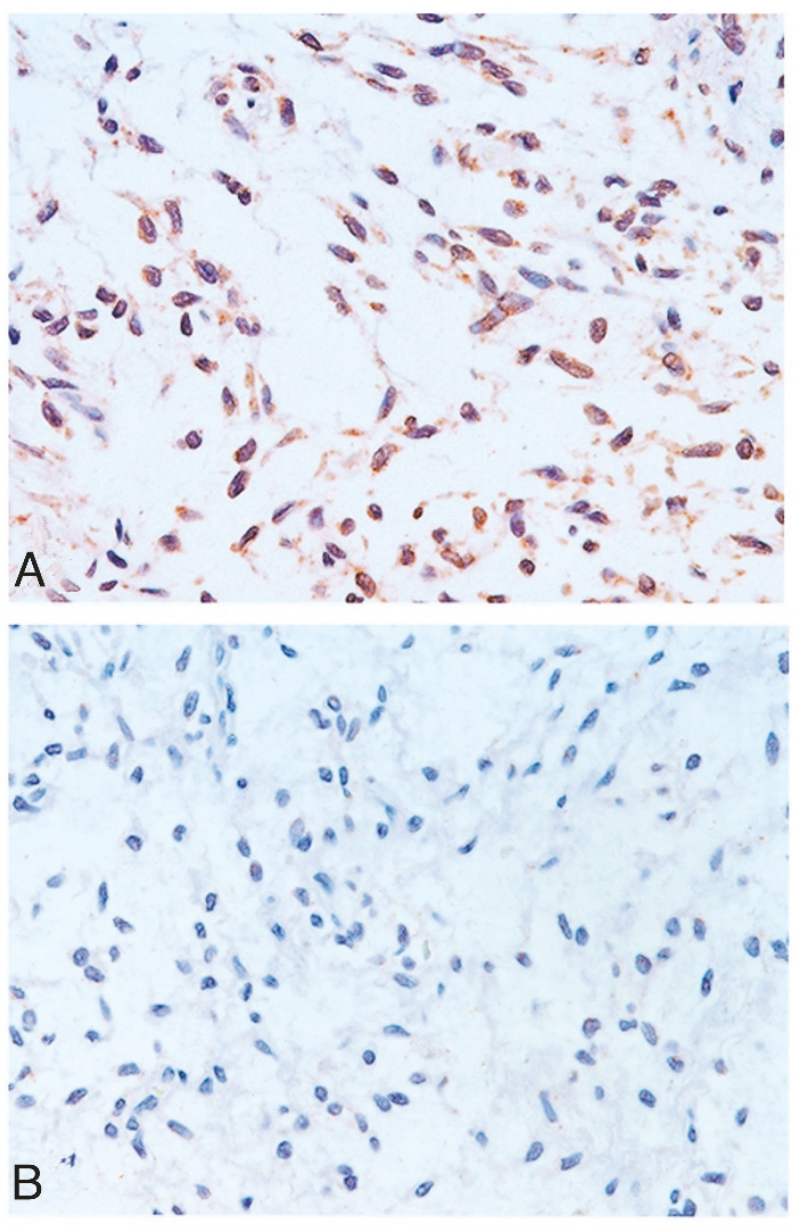

FIGURE 3. Expression of Class III $\beta$-tubulin in EMCS by in situ hybridization using an antisense oligonucleotide probe (A). The tumor is negatively stained with a sense probe $(\mathbf{B})$.

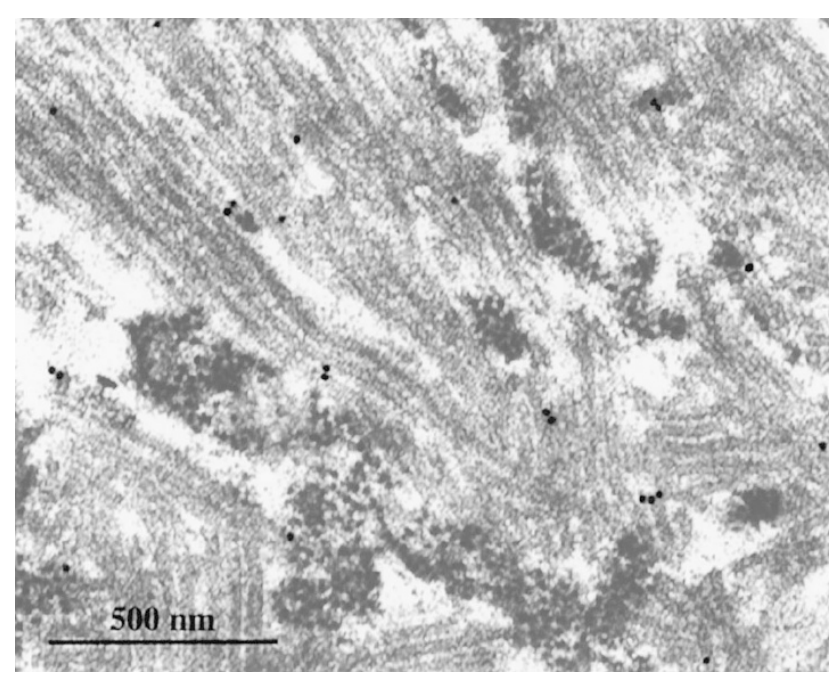

FIGURE 4. Immunolabeling of Class III $\beta$-tubulin in EMCS.

Immunogold particles are localized on microtubules aggregated within cisternae.

specific microtubule-related proteins, MAP-2, and Class III $\beta$-tubulin, as well as the detection of Class III $\beta$-tubulin gene expression by in situ hybridiza- 
tion, lend further support to the notion that a subset of extraskeletal myxoid chondrosarcoma shows neural-neuroendocrine differentiation. Our findings indicate that the abundant microtubules typically occurring in extraskeletal myxoid chondrosarcoma as aggregates in dilated endoplasmic reticulum or cisternae are similar to the microtubules of neurons and their derivatives.

Microtubules are ubiquitous organellae involved in various cellular functions such as mortility, mitosis, and intracellular transport. The $\beta$-tubulin isoforms have been found to differ in their cellular distributions within human tissues (30). Tubulin expression was recently reported in two extraskeletal myxoid chondrosarcomas and six chordomas: however, the tubulin isoforms were not determined (29). In this study, we selected a monoclonal antibody to the Class III $\beta$-tubulin isoform, TUJ1, which recognizes an epitope specifically expressed in neurons $(17,18)$. The Class III $\beta$-tubulin isoform as well as MAP-2 have recently been used as markers of neuroendocrine differentiation in pulmonary carcinoid and small cell carcinoma $(25,26)$.

The significance of Class III $\beta$-tubulin expression in extraskeletal myxoid chondrosarcoma is not entirely clear. Microtubule formation characteristically occurs in early cartilage development (31) and is of particular interest with regard to extraskeletal myxoid chondrosarcoma's histologic and histochemical resemblance to embryonal cartilage. Moreover, up-regulation of $\beta$-tubulin is believed to regulate differentiation and hypertrophy in growthplate chondrocytes (32). Which $\beta$-tubulin isoforms are expressed in developing cartilage and growth plate chondrocytes, however, is unknown.

MAP-2, high- and low-molecular weight components of the MAP family, is expressed mainly in neuronal cells and has been used as a sensitive and specific marker for cells with neural differentiation. The monoclonal antibody AP20 that was used in our study specifically detects $280-\mathrm{kDa}$-high molecular forms (MAP2a, MAP2b) of MAP-2. The expression of MAP-2 in 21/25 extraskeletal myxoid chondrosarcomas and $3 / 3$ chordomas in our study is in keeping with the consistent expression of tau, another microtubule-associated protein family that is required for axonal outgrowth and associated with neurodegenerative diseases such as Alzheimer's disease (29).

The expression of MAP- 2 and Class III $\beta$-tubulin in myxoid or chondroid tumors other than extraskeletal myxoid chondrosarcoma is not easily explained. Cartilage and neural tissue may have overlapping microtubule-related protein molecules, because pluripotent precursor cells of the neural crest can give rise to many derivatives, including neurons and cranial skeletal components such as cartilage, bone, and dermis (33). Besides, developing cartilage as well as notochordal remnants or the nucleus pulposus in the vertebral column of two fetuses ( 9 and 23 weeks of gestation, respectively) that we examined expressed MAP-2 but not Class III $\beta$-tubulin (data not shown). This finding may be related to the frequent expression of MAP-2 in chondroid tumors. Alternatively, the expressions of neuron-specific microtubule-related proteins could represent unscheduled or divergent differentiation in subsets of tumor cells, a phenomenon encountered in a variety of neoplastic conditions. To further address these issues, a large panel of tumors and tissues could be assessed for both markers.

The morphologic spectrum of extraskeletal myxoid chondrosarcoma is quite wide, and histologic recognition of its unusual variants may be very difficult (2). The ultrastructural demonstration of microtubular aggregates in extraskeletal myxoid chondrosarcoma is of limited diagnostic value because it occurs in only one third of cases and because similar structures may be seen in metastatic melanoma, osteosarcoma, embryonal rhabdomyosarcoma, and chordoma (34-38). The finding of MAP-2 and Class III $\beta$-tubulin in extraskeletal myxoid chondrosarcoma per se is probably of limited diagnostic value because these proteins are also expressed in myxoid and chondroid tumors simulating extraskeletal myxoid chondrosarcoma. However, this finding may help explain part of the reason behind neural-neuroendocrine differentiation seen in some extraskeletal myxoid chondrosarcomas.

In summary, our study demonstrates the presence of the neuron-specific microtubule-related proteins MAP-2 and class III $\beta$-tubulin in extraskeletal myxoid chondrosarcoma and further underscores the unique combination of potential chondroid and neural-neuroendocrine differentiation in this tumor.

\section{REFERENCES}

1. Enzinger FM, Siraki M. Extraskeletal myxoid chondrosarcoma: an analysis of 34 cases. Hum Pathol 1972;3:421-35.

2. Meis-Kindblom JM, Bergh P, Gunterberg B, Kindblom LG. Extraskeletal myxoid chondrosarcoma: a reappraisal of its morphologic spectrum and prognostic factors based on 117 cases. Am J Surg Pathol 1999;23:636-50.

3. Oliveira AM, Sebo TJ, McGrory JE, Gaffey TA, Rock MG, Nascimento AG. Extraskeletal myxoid chondrosarcoma: a clinicopathologic, immunohistochemical, and ploidy analysis of 23 cases. Mod Pathol 2000;13:900-8.

4. Okamoto S, Hisaoka M, Ishida T, Imamura T, Kanda $H$, Shimajiri S, et al. Extraskeletal myxoid chondrosarcoma: a clinicopathologic, immunohistochemical, and molecular analysis of 18 cases. Hum Pathol 2001;32:1116-24.

5. Labelle Y, Zucman J, Stenman G, Kindblom L-G, Knight J, Turc-Carel C, et al. Oncogenic conversion of a novel orphan nuclear receptor by chromosome translocation. Hum Mol Genet 1995;4:2219-26.

6. Antonescu CR, Argani P, Erlandson RA, Healey JH, Ladanyi M, Huvos AG. Skeletal and extraskeletal myxoid chondrosar- 
coma: a comparative clinicopathologic, ultrastructural, and molecular study. Cancer 1998;83:1504-21.

7. Sjögren H, Meis-Kindblom J, Kindblom A-G, Åman P, Stenman G. Fusion of the EWS related gene TAF2N to TEC in extraskeletal myxoid chondrosarcoma. Cancer Res 1999;59: 5064-7.

8. Sjögren H, Wedell B, Meis-Kindblom JM, Kindblom L-G, Stenman G. Fusion of the NH2-terminal domain of the basic helix-loop-helix protein TCF12 to TEC in an extraskeletal myxoid chondrosarcoma with translocation of $\mathrm{t}(9 ; 15)(\mathrm{q} 22$; q21). Cancer Res 2000;60:6832-5.

9. Tsuneyoshi M, Enjoji M, Iwasaki H, Shinohara N. Extraskeletal myxoid chondrosarcoma-a clinicopathologic and electron microscopic study. Acta Pathol Jpn 1981;31:439-47.

10. Kindblom LG, Angervall L. Myxoid chondrosarcoma of the synovial tissue. A clinicopathologic, histochemical, and ultrastructural analysis. Cancer 1983;52:1886-95.

11. Fletcher CD, Powell G, McKee PH. Extraskeletal myxoid chondrosarcoma: a histochemical and immunohistochemical study. Histopathology 1986;10:489-99.

12. Weiss SW. Ultrastructure of the so-called "chondroid sarcoma”: evidence supporting cartilaginous differentiation. Cancer 1976;37:300-6.

13. Harris M, Coyne J, Tariq M, Eyden BP, Atkinson M, Freemont AJ, et al. Extraskeletal myxoid chondrosarcoma with neuroendocrine differentiation: a pathologic, cytogenetic, and molecular study of a case with a novel translocation $\mathrm{t}(9 ; 17)(\mathrm{q} 22 ; \mathrm{q11}$.2). Am J Surg Pathol 2000;24:1020-6.

14. Chhieng DC, Erlandson RA, Antonescu C, Ladanyi M, Rosai J. Neuroendocrine differentiation in adult soft tissue sarcoma with features of extraskeletal myxoid chondrosarcoma: report of seven cases [abstract]. Mod Pathol 1998;11:8A.

15. Goh YW, Spagnolo DV, Platten M, Caterina P, Fisher C, Oliveira AM, et al. Extraskeletal myxoid chondrosarcoma: a light microscopic, immunohistochemical, ultrastructural and immuno-ultrastructural study indicating neuroendocrine differentiation. Histopathology 2001;39:514-24.

16. DeBlois G, Wang S, Kay S. Microtubular aggregates within rough endoplasmic reticulum: an unusual ultrastructural feature of extraskeletal myxoid chondrosarcoma. Hum Pathol 1986;17:469-75.

17. Sullivan KF, Cleveland DW. Identification of conserved isotype-defining variable region sequences for four vertebrate $\beta$-tubulin polypeptides classes. Proc Natl Acad Sci U S A 1986;83:4327-31.

18. Frankfurter A, Binder LI, Rebhun LI. Limited tissue distribution of a novel beta-tubulin isoform [abstract]. J Cell Biol 1986;103:273a.

19. Lewis SA, Cowan NJ. Complex regulation and functional versatility of mammalian $\alpha$ - and $\beta$-tubulin isotypes during the differentiation of testis and muscle cells. J Cell Biol 1988;106:2023-33.

20. Dráberová E, Lukáš Z, Ivanyi D, Viklický V, Dráber P. Expression of class III $\beta$-tubulin in normal and neoplastic human tissues. Histochem Cell Biol 1998;109:231-9.

21. Johnson GVW, Jope RS. The role of microtubule-associated protein 2 (MAP2) in neuronal growth, plasticity, and degeneration. J Neurosci Res 1992;33:505-12.

22. Huber G, Matus A. Differences in the cellular distribution of two microtubule-associated proteins, MAP1 and MAP2, in the rat brain. J Neurosci 1984;4:151-60.
23. Matus A, Bernhardt R, Hugh-Jones T. High molecular weight microtubule-associated proteins are preferentially associated with dendritic microtubules in brain. Proc Natl Acad Sci U S A 1981;78:3010-4.

24. Hallman JR, Fang D, Setaluri V, White WL. Microtubule associated protein (MAP-2) expression defines the companion layer of the anagen hair follicle and an analogous zone in the nail unit. J Cutan Pathol 2002;29:549-56.

25. Katsetos CD, Kontogeorgos G, Geddes JF, Herman MM, Tsimara-Papastamatiou H, Yu Y, et al. Differential distribution of the neuron-associated class III beta-tubulin in neuroendocrine lung tumors. Arch Pathol Lab Med 2000;124: 535-44.

26. Liu Y, Sturgis CD, Grzybicki DM, Jasnosz KM, Olson PR, Tong M, et al. Microtubule-associated protein-2: a new sensitive and specific marker for pulmonary carcinoid tumor and small cell carcinoma. Mod Pathol 2001;14:880-5.

27. Katsetos CD, Del Valle L, Geddes JF, Assimakopoulou M, Legido A, Boyd JC, et al. Aberrant localization of the neuronal class III $\beta$-tubulin in astrocytomas. A marker for anaplastic potential. Arch Pathol Lab Med 2001;125:613-24.

28. Cummings TJ, Shea CR, Reed JA, Burchette JL, Prieto VG. Expression of the intermediate filament peripherin in extraskeletal myxoid chondrosarcoma. J Cutan Pathol 2000;27: 141-6.

29. Hu B, McPhaul L, Cornford M, Gaal K, Mirra J, French SW. Expression of tau proteins and tubulin in extraskeletal myxoid chondrosarcoma, chordoma, and other chondroid tumors. Am J Clin Pathol 1999;112:189-93.

30. Roach MC, Boucher VL, Walss C, Ravdin PM, Luduena RF. Preparation of a monoclonal antibody specific for the class I isotype of $\beta$-tubulin: the $\beta$ isotypes of tubulin differ in their cellular distributions within human tissues. Cell Motil Cytoskeleton 1998;39:273-85.

31. Searls RL, Hilfer SR, Mirow SM. An ultrastructural study of early chondrogenesis in the chick wing bud. Dev Biol 1972; 28:123-37.

32. Farquharson C, Lester D, Seawright E, Jefferies D, Houston B. Microtubules are potential regulators of growth-plate chondrocyte differentiation and hypertrophy. Bone 1999;25: 405-12.

33. Baker CVH, Bronner-Fraser M, Le Douarin NM, Teillet M-A. Early- and late-migrating cranial neural crest cell populations have equivalent development potential in vivo. Development 1997;124:3077-87.

34. MacKay B, Ayala AG. Intracisternal tubules in human melanoma cells. Ultrastruct Pathol 1980;1:1-6.

35. Marquart KH. Intracisternal crystalline arrays of coated parallel tubules in cells of a human osteosarcoma. Virchows Arch A Pathol Anat Histol 1981;391:309-13.

36. Valderrama E, Kahn LB, Lipper S, Marc J. Chondroid chordoma. Electron-microscopic study of two cases. Am J Surg Pathol 1983;7:625-32.

37. Ueda Y, Nakanishi I, Tsuchiya H, Tomita K. Microtubular aggregates in the rough endoplasmic reticulum of sacrococcygeal chordoma. Ultrastruct Pathol 1991;15:77-82.

38. Tsuchida R, Ishida T, Uozaki H, Bessho F, Machinami R. Microtubular aggregates within the rough endoplasmic reticulum of embryonal rhabdomyosarcoma cells: a case report. Ultrastruct Pathol 1999;23:193-8. 